\title{
Modification of aluminum surfaces by supersonic plasma sputtering
}

\author{
Sergey Ilinykh ${ }^{1, *}$, Anastasia Krivorigova ${ }^{1,2}$, Nina Ilinykh $^{1}$, Boris Gelchinski ${ }^{1}$, and Leopold \\ Leontiev $^{1}$ \\ ${ }^{1}$ Institute of Metallurgy, Ural Branch of the Russian Academy of Sciences, 101 Amundsena Str., \\ Ekaterinburg 620016, Russian Federation \\ ${ }^{2}$ Ural Institute of State Fire Service of EMERCOM of Russia, 22 Mira Str., Ekaterinburg, Russian \\ Federation
}

\begin{abstract}
Surface engineering allows you to change the physical and chemical properties of the surface layers of materials by modifying or applying protective coatings using various methods. Plasma technologies are widely used in various branches of engineering to produce hardening, wear-resistant, heat-resistant, corrosion-resistant, protective and decorative and other types of coatings that significantly improve the performance properties of products. In this work the results of laboratory studies of the physical and mechanical properties of Ni-B-Cr-Si coatings deposited by supersonic plasma deposition on an aluminum substrate are presented. It is shown that the use of this method of modification of metal surfaces is advisable.
\end{abstract}

\section{Introduction}

Nowadays plasma modification, as one of the methods of hardening by heating sources with a high power density, is now widely used. The plasma jet generated by the plasma torch has unique features, namely: the possibility of thermal and gas-dynamic effects; the ease of entering any gaseous compounds or vapors of liquid reagents; the presence of lowfrequency and high-frequency plasma pulsations; providing a directed flow of ionized, excited particles, etc. All these factors contribute to the possibility of using plasma flow to strengthen metal surfaces [1-5].

The purpose of this work is to study the possibility of using supersonic plasma spraying to increase the service life of special equipment parts operating in extreme conditions.

By the method of supersonic plasma spraying using air-methane mixture as the plasmaforming gas, laboratory samples of coatings PGSR-2 (Ni-0.5 C-15Cr-3.2 Si-2B), PGSR-4 (Ni-1C-17Cr-4.1 Si-3.6 B) on aluminum substrate AL9 (aluminum-silicon, silumin (6.0 to $13 \% \mathrm{Si})$ ) were obtained.

\footnotetext{
* Corresponding author: sergil1957@mail.ru
} 


\section{Method of investigation}

Conducted spraying of powders PGSR-2 (Ni-0.5 C-15Cr-3.2 Si-2B), PGSR-4 (Ni-1C-17Cr4.1 Si-3.6 B) on the connection head fire hose was carried out with using of equipment a supersonic plasma spraying "MAK 100" developed of IMET UB RAS (Fig.1). Laboratory tests of the obtained coatings were carried out. The dynamics of mechanical properties changing the quality of (hardness, wear resistance) in coatings with a large number of impurities is shown. Mechanical tests for three-point bending of the coating were performed.

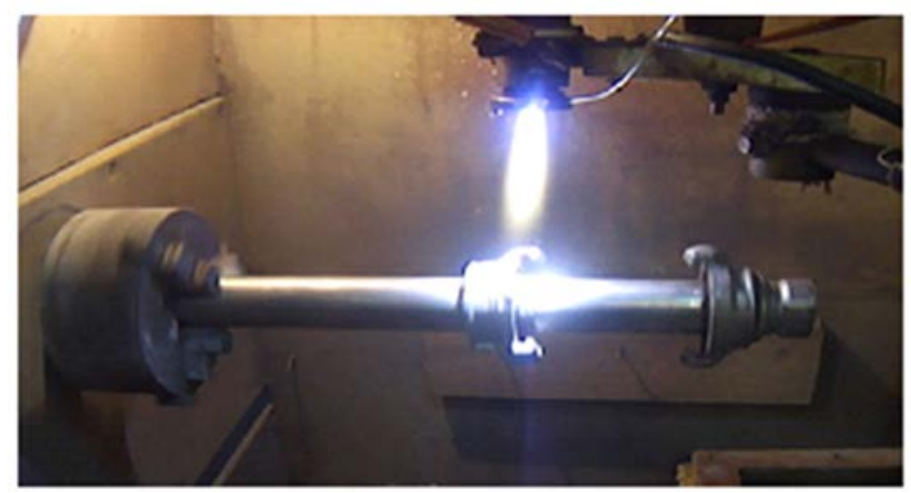

Fig. 1. Deposition of a gas-thermal coating to the connecting head of the fire hose.

The laboratory samples of $\mathrm{Ni}-\mathrm{B}-\mathrm{Cr}-\mathrm{Si}$ powder coatings deposited by a supersonic plasma jet using a mixture of air and methane as the plasma-forming gas were obtained. Selected spray modes: current-150 A, voltage-300 V, operating pressure- 4 atm, spray distance-200 mm). Aluminum AL9 was used as the substrate material for spraying.

Investigation of the microhardness and structure of the coating were carried out on a transverse metallographic section. Microhardness was measured using a standard method using a PMT-3 microhardness meter equipped with a monitor and a digital video camera. The study of the microstructure of the sputtered surface by a plasma jet was carried out by computer metallographic analysis using the Siams-600 image analysis system.

Tribological tests of the friction pair "samples made of duralumin with plasma coatingsteel X12M" were carried out on a laboratory installation - a disk friction machine in a lubricant environment and in an air environment without lubrication according to the "finger - disk" loading scheme. Friction occurred under conditions of sliding of the end surface $(7 \times 7 \mathrm{~mm})$ of duralumin samples with coatings applied on them (finger) on the flat surface of a rotating disk made of steel X12M (hardness $63 \mathrm{HRC}$, disk diameter $150 \mathrm{~mm}$, disk thickness $10 \mathrm{~mm})$. The samples were tested under various normal loads $(\mathrm{N}=2.7-50.0$ $\mathrm{kgf})$, sliding speeds $(\mathrm{V}=3.75-12.0 \mathrm{~m} / \mathrm{s})$, and friction paths $(\mathrm{L}=2250-19730 \mathrm{~m})$. Friction pairs were tested in two media: 1) in the presence of a liquid lubricant (industrial grade I-30 oil), which was continuously fed to the friction contact zone by a drip method at a speed of 60 drops per minute; 2) without the supply of lubricant. During the tests, the friction force was continuously measured and recorded. Measurements for calculating the coefficient of friction were carried out using an elastic element with resistance load cells pasted on it. The coefficient of friction was determined as the quotient of the friction force divided by the normal load. Before and after the tests, the samples were weighed on analytical scales, determining changes in the mass of the sample during the test $\Delta \mathrm{P}=\mathrm{P}_{1}-\mathrm{P}_{2}$, where $\mathrm{P}_{1}$ is the initial mass of the sample, $\mathrm{P}_{2}$ is the mass of the sample after the test. 
The cohesive strength of gas-thermal coatings affects their performance properties, primarily the preservation of the integrity of the applied layer under the influence of deformation forces on the coating and the base product. Mechanical tests for three-point bending were performed on a universal testing machine ZWICK Z050 (BT1FR050THW/A1K). The test was performed with a traverse speed of $2 \mathrm{~mm} / \mathrm{min}$ and a preload of $5 \mathrm{~kg}$.

\section{Results and discussion}

\subsection{Microstructure of plasma coatings}

The use of high-speed plasma (with speeds of approach of the sprayed particle to the surface of the substrate of $600-850 \mathrm{~m} / \mathrm{s}$ ) allows as to implement multi-purpose protection of metal products. The most important feature of the structures obtained by plasma spraying is a high degree of dispersion, which determines the complex of operational characteristics. Fig.2-a shows the microstructure of the PGSR-2 coating. The coating is characterized by the presence of porosity over the entire thickness; the pores have an irregular shape and sizes from a few microns to 100 microns. The coating area at the border with the substrate is characterized by a more uniform structure. The powder particles are sufficiently melted, and the coating has a layered structure with well-deformed particles throughout the coating body. The pores are both rounded and elongated. The fusing line with the substrate is quite smooth and dense.

The microstructure of the PGSR 4 coating is shown in Fig.2-b. The coating of standard $\mathrm{Ni}-\mathrm{Cr}-\mathrm{B}-\mathrm{Si}$ powder is characterized by high density, low porosity, and a smooth border with the substrate. The pores are small and located far from each other. There are very small pores formed, apparently, as a result of degassing of the molten material of the particles during their crystallization. The oxide films are thin, but they are located along the "base-coating" interface close enough to each other, which indicate that the powder particles burn out.

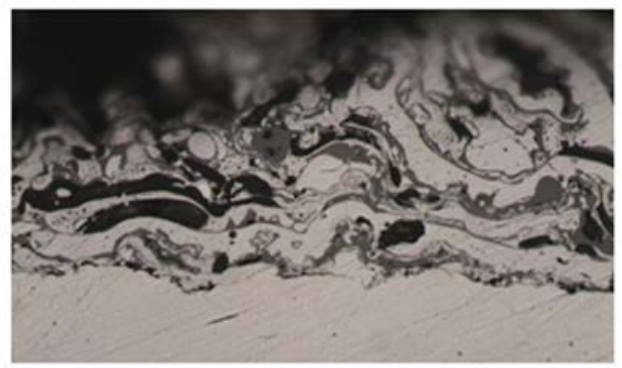

a

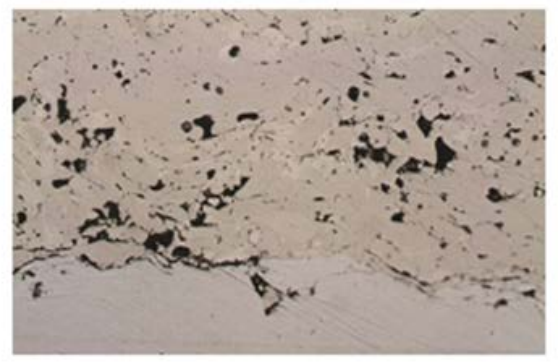

6

Fig. 2. Microstructure of PGSR-2 (a) and PGSR-4 (b) coatings, image X500.0

\subsection{Microhardness}

On average, the level of microhardness of PGSR-2 and PGSR-4 coatings is several times higher than the microhardness of the base. The image of the prints of microhardness measurements are shown in Fig.3, a and b. The numerical results of the measurements are presented in the Table 1. 


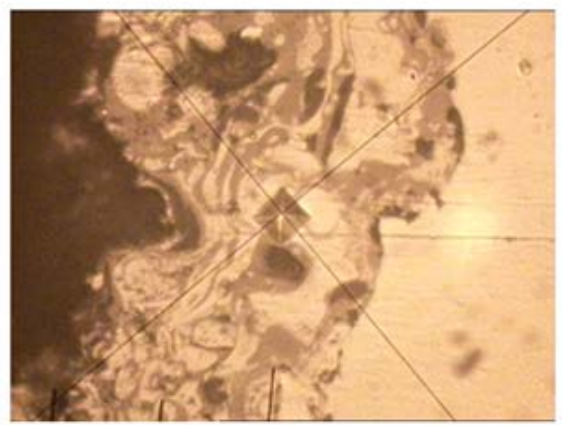

a

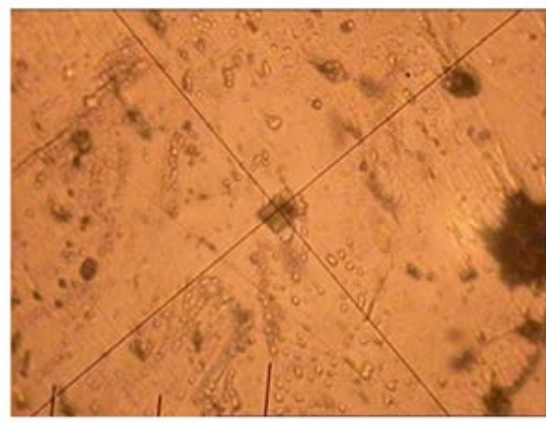

б

Fig. 3. The image of the performed microhardness measurements of coatings PGSR-2 (a) and PGSR4 (b), image X 500.0

Table 1. Results of microhardness measurements.

\begin{tabular}{|c|c|c|c|}
\hline \multirow{2}{*}{ № } & \multirow{2}{*}{ Designation } & PGSR-2 & PGSR-4 \\
\hline & & \multicolumn{2}{|c|}{$\mathrm{HV}$} \\
\hline 1 & Coating & 310,5 & 558,1 \\
\hline 2 & Coating & 261,7 & 540,4 \\
\hline 3 & Coating & 289,4 & 407,4 \\
\hline 4 & Coating & 318 & 447 \\
\hline 5 & Coating & 257 & 702,7 \\
\hline 6 & Coating & 267,5 & 526,7 \\
\hline 7 & Coating & 277,6 & 591,9 \\
\hline
\end{tabular}

\subsection{Tribological tests of coated samples in the presence of a lubricant}

There were examined the samples PGSR-2, PGSR-4 coatings (coatings thickness $\mathrm{h}=0.5-1$ $\mathrm{mm}$ ). The results of tribological tests are presented in Tables 2 and 3 , where $\mathrm{N}$ is the normal load, $\mathrm{V}$ is the sliding speed, $\Delta \mathrm{P}$ is the change in the mass of the sample, $\mathrm{f}_{\text {fmax }}$ is the maximum coefficient of run-in friction, $f_{\max }$ is the maximum coefficient of friction (breakdowns), $\mathrm{f}_{\text {mid }}$ is the average steady-state coefficient of friction.

In many tests, "negative" wear was observed, which was manifested in an increase in the mass of the sample during the test $\left(\mathrm{P}_{2}-\mathrm{P}_{1}\right)$ and was associated with the impregnation of coatings with grease. The increase in the mass of the sample due to lubrication prevailed in this case over the decrease in mass as a result of wear of the coating. In some severe friction regimes were observed the so-called "burning" lubricant, as a result of intense frictional heating the temperature of the lubricant in the zone of friction contact above critical and lubrication "smoked".

The study of the main tribological properties (wear resistance and coefficient of friction) of samples with coatings under conditions of sliding friction on steel X12M at normal loads on the sample of $25-50 \mathrm{kgf}$ and linear speeds of $3.75-12 \mathrm{~m} / \mathrm{s}$ in the presence of liquid lubricant showed that the PGSR-4 coating has a higher performance compared to the PGSR-2 coating.

Additional tests for sliding friction without lubrication also revealed that the PGSR-4 coating is superior to the PGSR-2 coating. The residual lubricant accumulated in the coating pores has a positive effect on the tribological properties of coatings. During the tests, the destruction (peeling) of the coatings was not observed. 
Table 2. Results of tribological tests with lubrication.

\begin{tabular}{|c|c|c|c|c|c|c|}
\hline \multirow{3}{*}{$\mathrm{N}, \mathrm{kgf}$} & \multirow{2}{*}{$\mathrm{V}, \mathrm{m} / \mathrm{s}$} & \multirow{2}{*}{$\mathrm{L}, \mathrm{m}$} & \multicolumn{2}{|c|}{ PGSR-2 } & \multicolumn{2}{c|}{ PGSR-4 } \\
\cline { 3 - 7 } & & & $\mathrm{P}, \mathrm{mg}$ & $\mathrm{f}_{\text {mid }}$ & $\mathrm{P}, \mathrm{mg}$ & $\mathrm{f}_{\text {mid }}$ \\
\hline \multirow{5}{*}{25,0} & 3,75 & 6750 & $-3,00$ & 0,04 & $-1,20$ & 0,05 \\
\cline { 2 - 7 } & 9,0 & 16200 & $-3,00$ & 0,04 & $-1,20$ & 0,06 \\
\cline { 2 - 7 } & 12,0 & 19730 & $-3,05$ & 0,04 & $-1,50$ & 0,04 \\
\hline \multirow{5}{*}{50,0} & 3,75 & 6750 & $-2,5$ & 0,05 & $-1,70$ & 0,04 \\
\cline { 2 - 7 } & 6,0 & 10800 & $-2,5$ & 0,02 & $-1,5$ & 0,03 \\
\cline { 2 - 7 } & 6,5 & 11700 & $-2,0$ & 0,08 & $-1,0$ & 0,02 \\
\cline { 2 - 7 } & 7,75 & 13950 & $-3,25$ & 0,02 & $-1,35$ & 0,02 \\
\cline { 2 - 7 } & 9,0 & 16200 & $-3,40$ & 0,02 & $-1,40$ & 0,03 \\
\cline { 2 - 7 } & 10,5 & 18900 & $-2,00$ & 0,02 & $-1,00$ & 0,02 \\
\cline { 2 - 7 } & 12,0 & 19730 & 3,00 & 0,07 & 1,00 & 0,05 \\
\hline
\end{tabular}

Table 3. The results of tribological tests without a lubricant.

\begin{tabular}{|c|c|c|c|c|c|c|}
\hline \multirow{2}{*}{$\mathrm{N}, \mathrm{kgf}$} & \multirow{2}{*}{$\mathrm{V}, \mathrm{m} / \mathrm{s}$} & \multirow{2}{*}{$\mathrm{L}, \mathrm{m}$} & \multicolumn{2}{|c|}{ PGSR-2 } & \multicolumn{2}{|c|}{ PGSR-4 } \\
\cline { 4 - 7 } & & & $\mathrm{P}, \mathrm{mg}$ & $\mathrm{f}_{\text {mid }}$ & $\mathrm{P}, \mathrm{mg}$ & $\mathrm{f}_{\text {mid }}$ \\
\hline \multirow{2}{*}{2,7} & 3,75 & 3375 & 1,1 & 0,17 & 1,5 & 0,25 \\
\cline { 2 - 7 } & 6,5 & 3900 & 3,2 & 0,30 & 3,25 & 0,52 \\
\cline { 2 - 7 } & 12,0 & 5400 & 3,6 & 0,30 & 3,65 & 0,41 \\
\hline \multirow{2}{*}{7,5} & 3,75 & 3375 & 10,7 & 0,47 & 12,0 & 0,55 \\
\cline { 2 - 7 } & 6,0 & 3900 & 25,5 & 0,45 & 26,5 & 0,60 \\
\hline 25,0 & 3,75 & 2250 & 30,0 & 0,36 & 30,5 & 0,47 \\
\hline
\end{tabular}

\subsection{Mechanical tests for three-point bending of the coating}

Three-point bending tests were performed on a Zwick/Roell z050 universal testing machine (BT1-FR050THW/A1K). The distance between the supports was set to $20 \mathrm{~mm}$; the plate was laid with the coating down so that the loading occurred from the side of the substrate. The speed of movement of the movable traverse was set to $4 \mathrm{~mm} / \mathrm{min}$ and three tests of each coating were performed. Photos of coated plates after testing with characteristic failures for each coating and application conditions are shown in Fig.4. Three-point bending tests have shown that samples PGSR-2 and PGSR-4 coatings do not have a failure with a central crack. There are layers of coatings on the edges of the bend.

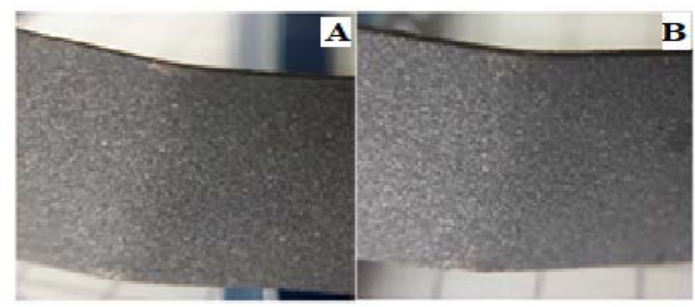

Fig. 4. Typical coating failures: A-PGSR-2; B-PGSR-4. 
Rockwell hardness was measured to determine the strength characteristics of coatings obtained by supersonic deposition of PGSR-2 and PGSR-4 and to indirectly evaluate their performance properties. The hardness was measured using an ultrasonic meter UZIT-3 (measurement limits from 20-70 HRC, measurement error not exceeding $\pm 2.0 \mathrm{HRC}$ ). The results of measuring the hardness (HRC) of coatings on samples PGSR-2 and PGSR-4 are shown in Table 4.

Table 4. The results of hardness measurement (HRC).

\begin{tabular}{|c|c|c|}
\hline № & PGSR -2 & PGSR -4 \\
\hline 1 & 70,5 & 88 \\
\hline 2 & 71,4 & 79,5 \\
\hline 3 & 67,2 & 84,5 \\
\hline 4 & 65,2 & 78,8 \\
\hline 5 & 64,1 & 87,7 \\
\hline 6 & 70,1 & 80 \\
\hline 7 & 69,6 & 87,2 \\
\hline 8 & 74,2 & 71,9 \\
\hline
\end{tabular}

The spread of hardness values is related to the structural features of the coating, its lamellar structure, as well as the multiphase nature of the applied composite material containing areas with different hardness. Rockwell hardness measurements give us an average picture of the hardness in the direction perpendicular to the layer plane, as opposed to microhardness, which characterizes the properties of individual coating phases.

The measurement results obtained for three-point bending [6], Table 5, show that irreversible deformation of the samples begins at values from 140-160 N/ mm2.

Table 5. Measurement results obtained for three-point bending

\begin{tabular}{|c|c|c|c|c|}
\hline № & Coating & $\mathrm{A}, \mathrm{mm}^{2}$ & $\mathrm{E}_{\text {mod, }} \mathrm{kN} / \mathrm{m}^{2}$ & $\mathrm{~F}_{\max }, \mathrm{MPa}$ \\
\hline 1 & \multirow{3}{*}{ PGSR -2 } & 12,49 & 132,93 & 719,14 \\
\hline 2 & & 12,58 & 173,35 & 764,42 \\
\hline 3 & & 14,29 & 144,44 & 647,58 \\
\hline 4 & \multirow{3}{*}{ PGSR -4 } & 12,99 & 100,17 & 628,39 \\
\hline 5 & & 13,95 & 120,72 & 655,79 \\
\hline 6 & & 11,88 & 165,63 & 727,40 \\
\hline
\end{tabular}

\section{Conclusions}

By the method of supersonic plasma spraying using air-methane mixture as the plasmaforming gas, laboratory samples of coatings PGSR-2 (Ni-0.5 C-15Cr-3.2 Si-2B), PGSR-4 (Ni-1C-17Cr-4.1 Si-3.6 B) on aluminum substrate AL9 (aluminum-silicon, silumin (6.0 to $13 \% \mathrm{Si})$ ) were obtained. The properties of the obtained coatings were studied. Based on the results of the research, the following conclusions can be drawn:

1. Study of the main tribological properties (wear resistance and coefficient of friction) of samples with coatings under friction conditions showed that the PGSR-4 coating has a higher performance compared to the PGSR-2 coatings.

2. The adhesive and cohesive properties of the PGSR-2 and PGSR-4 coatings deposited on an aluminum substrate were studied. The coatings are sufficiently strong and can withstand stresses in the area of elastic deformation. It is shown that during the bending test, there is a peeling of the coating without the formation of cracks. 
3. The use of Ni-B-Cr-Si as wear-resistant technological coatings is more economically feasible than a product made of duralumin.

4. Coatings based on PGSR-2 and PGSR-4 have a good strength properties and, taking into account good tribological properties, can be recommended for use in various components of fire equipment machines and mechanisms (pumping equipment, connecting elements).

The reported study was funded by RFBR, project number №20-21-00063 Rosatom

\section{References}

1. Ju.S. Borisov, Ju.A. Charlamov, S.L. Sidorenko at al. Thermal coatings of powder materials (Naukova Dumka, Kiev, 1987) (in Russian)

2. S.A. Ilinykh, S.A. Krasikov, A.A. Ponomarenko, O.A. Sitnikova, B.R. Gelchinsky, V.A. Krashaninin. Phase formation during metallothermic production of Al-Ti-Ni-Mo alloys, Proceedings of the 13th International scientific and technical conference "Surface engineering and product renovation" (ATM of Ukraine, Kiev, p.116 (2013))

3. L.I. Tushinsky, A.V. Plokhov. Investigation of the structure and physical and mechanical properties of coatings (Nauka, Novosibirsk, 1986).

4. E.A. Astakhov. Scientific and technological bases for controlling the properties of detonation coatings: Dis. Sciences: 05.03.06 (NAS of Ukraine; E. O. Paton Institute of electric welding, Kiev, 2005)

5. V.Yu. Ulyanitsky, M.V. Nenashev, V.V. Kalashnikov at al. Experience in research and application of technology for applying detonation coatings, Proceedings of the Samara scientific center of the Russian Academy of Sciences, v.12, p.569 (2010)

6. Silvano Rech, Andrea Trentin, Simone Vezzu. Different Cold Spray Deposition Strategies: Single- and Multi-layers to Repair Aluminium Alloy Components, Journal of Thermal Spray Technology, v.23, pp.1237-1250 (2014) 